Review

\title{
Physical Inactivity from the Viewpoint of Evolutionary Medicine
}

\section{Sylvia Kirchengast}

Department of Anthropology, University of Vienna, Althanstrasse 13, Vienna A-1090, Austria; E-Mail: sylvia.kirchengast@univie.ac.at; Tel. +431427754712

Received: 1 January 2014; in revised form: 5 February 2014 / Accepted: 28 April 2014/

Published: 2 June 2014

\begin{abstract}
Activity patterns of recent Homo sapiens are characterized by a sedentary life style and consequently by exercise deficiency. This lack of physical activity increases the risk of various chronic non-communicable diseases and reduces health related quality of life. From the perspective of evolutionary medicine, the high rates of non-communicable disease among contemporary industrialized populations may be interpreted as the result of a mismatch between high rates of physical activity in the adaptively relevant (ARE) and sedentary recent life circumstances. Public transport, cars, elevators, supermarkets and internet shopping diminished daily physical activities dramatically, therefore recent Homo sapiens suffer from the consequences of a convenient life style, which is completely new in our evolution and history. The only possibility to increase physical activity and enhance health and well-being is through sporting activities during leisure time.
\end{abstract}

Keywords: physical activity; sports; evolutionary medicine; sedentary life style; health risks

\section{Introduction}

Daily life in modern industrialized societies is characterized by a low rate of physical activity. There is no need to run, to climb up trees or mountains or even to walk in order to procure food or shelter. Urbanization and a high degree of technological development have resulted in a generally low occupational physical activity and only few individuals are motivated to be physically active during leisure time. Consequently, recent Homo sapiens living in western industrialized countries can be described as a sedentary individual working with its fingertips and spending leisure time by watching TV or surfing the Internet [1]. On the other hand, there is an omnipresent enormous surplus of 
tasty food rich in refined sugars and unsaturated fat. As a consequence, Homo sapiens experience a chronic positive energy balance resulting in high rates of overweight and obesity but also high rates of various chronic diseases, such as diabetes mellitus type 2, cardiovascular symptoms, hypertension, hypercholesterinemia, osteoporosis, and also some cancers [2-4]. Beside these metabolic disturbances, physical inactivity is associated with various psychological problems and neurological syndromes such as dementia [5,6]. However, why do Homo sapiens prefer this kind of inactive life style which is clearly associated with major health risks, a low health related quality of life and increased mortality rates?

The aim of this review is to specifically address the impact a sedentary physical inactive lifestyle has on health and disease from the viewpoint of evolutionary medicine.

\section{The Terms Physical Activity and Physical Fitness}

Before discussing physical inactivity as an important factor of health risk, we have to define the terms physical activity and physical fitness. From a biomechanical point of view, physical activity can be characterized as a series of behaviors which involve bodily movements produced by skeletal muscles [7]. Consequently, movement is the substrate of physical activity. Physical activity comprises all kinds of movements and locomotion essential for subsistence, tool making, occupation, work, play exercise, and many other activities such as ritual behavior like dancing. Physical activity is closely associated with the term physical fitness. Physical fitness is defined as a state or a condition which permits the individual to carry out her/his daily activities without undue fatigue and with sufficient reserve to enjoy active leisure pursuits [7]. While physical fitness is mainly viewed in terms of muscular strength, cardiorespiratory endurance, endurance, musculoskeletal functions and body composition, physical activity is largely focused on from the viewpoint of biomedicine and public health [7]. In particular, the importance of physical activity for sufficient energy expenditure is pointed out. Sufficient physical activity is seen as an essential factor to reduce health risks and increase general health. Consequently, physical inactivity and a lack of physical fitness are identified as major risk factors for increased morbidity and mortality as well as for reduced health related quality of life.

\section{Physical Inactivity as a Major Health Risk Factor}

Biological and medical consequences of physical inactivity were first described by the Greek physician Hippocrates about 2400 years ago. "That which is used develops, and that which is not used wastes away... If there is any deficiency in food or exercise the body will fall sick". Hippocrates associated a lack of physical activity clearly with poor health. On the other hand, physical activity was used as efficient treatment of obesity by the second century AD physician Galenos of Pergamon (129-200 AD) "...I reduced a huge fat fellow to a moderate size in a short time, by making him run every morning until he fell into a profuse sweat" [8]. Hippocrates and Galenos' early writings have been of enormous clinical importance until recent times. We all know that physical inactivity due to continuous bed rest for a longer time but also staying in a microgravity environment of space results in atrophy of muscle mass and a reduction of bone mass and bone density. Furthermore, excessive inactivity enhances rapid disruption of normal function in tissues as well as cells and gene expression $[3,4]$. According to the American Centers of Disease Control (CDC), "no regular exercise" accounted 
for $23 \%$ of death in the United States in 1986 . These deaths are attributable to nine chronic diseases. Furthermore, poor diet and physical inactivity were the second leading cause of preventable deaths from 1980-2002 [9]. An inverse association between lifetime physical activity all-cause mortality was reported by the US Department of Health and Human Services [10]. According to this study, lifetime inactive individuals have about $30 \%$ higher risk of dying compared with life time active individuals $[2,10]$. The adverse health effects of an inactive lifestyle and a lack of exercise have been verified by an enormous amount of epidemiological studies. In detail, physical inactivity or a lack of lifetime exercise increases the relative risk of coronary heart disease by $45 \%$, stroke by $60 \%$, hypertension by $30 \%$, and diabetes type 2 by $50 \%$ in the United States [10]. An analysis of the effects of physical inactivity on major non-communicable diseases such as type 2 diabetes, coronary heart disease, high blood pressure, stroke breast cancer, colon cancer but also depression showed that physical inactivity has a major health effect worldwide [11]. Physical inactivity causes $6 \%$ of the burden of disease from coronary heart disease, $7 \%$ of type 2 diabetes, $10 \%$ of breast cancer, and $10 \%$ of colon cancer. Physical inactivity causes $9 \%$ of premature mortality. The authors estimated that elimination of physical inactivity would increase the life expectancy of the world population by 0.68 years [11]. The American Diabetes Association stated on their website that "type 2 diabetes is associated with physical inactivity". According to the American Heart Association, "An inactive lifestyle is a risk factor for coronary heart disease" [3]. Hypertension, type 2 diabetes and coronary artery disease-collectively referred to as "syndrome X"-is strongly associated with insulin resistance. Physical activity reduces the risk of insulin resistance. On the one hand, acute exercise, aerobic as well as strength, enhance glucose uptake by skeletal muscle tissue, while on the other hand, chronic training increases skeletal muscle insulin sensitivity and reduces plasma insulin levels [12]. The Harvard Nurse Health Study indicated a higher prevalence of breast cancer $(22 \%)$, colon cancer $(85 \%)$, coronary heart disease (43\%), gallstones (49\%), diabetes type $2(85 \%)$, and ischaemic stroke (117\%) among participants who were less than 2.5 hours per week moderately physically active compared with participants who had more than 2.5. hours per week of physical activity [4].

Physical inactivity is also discussed as the main reason for the recent worldwide epidemic of obesity [13]. A sedentary life style enhances body fat accumulation and increases body weight even among children and adolescents. Obesity in turn is an independent risk factor for metabolic and cardiovascular diseases and it increases morbidity and mortality among adults but also among children.

Furthermore, physical inactivity enhances the risk of developing colon cancer by $41 \%$ and the risk of developing breast cancer by $31 \%$. Frisch et al. reported a decreased breast cancer risk among women who were involved in athletics in college compared with women who were not involved in athletics during college time [14]. These findings were corroborated by several epidemiologic studies which found an inverse association between physical activity and breast carcinoma risk [15].

Physical inactivity has also a major impact on bone and muscle health. Physical activity during childhood and adolescence promotes the formation of dense and well-mineralized bones [16]. Mineral density and structural geometry are key elements to protect bones from mechanical stresses. A physically inactive life style, however, accelerates bone and increases the risk of developing osteoporosis [17]. Physical inactivity however has not only an adverse impact on bone mass and bone density, it results in muscle loss and the development of sarcopenia too. Sarcopenia, from the Greek "poverty of flesh", refers to the state of pathologically reduced skeletal muscle mass [18]. Skeletal 
muscle represents not only the largest component at the tissue-organ level of body composition, it is also essential for locomotion and mobility. Sarcopenia has dramatic consequences such as impaired functional performance, increased risk of falls and - in association with osteoporosis - consequently an increased risk of fragility fractures [19-21]. This is especially true of elderly people suffering from the frailty syndrome which is also associated with physical inactivity. Consequently, the risk of fatal fractures is enhanced among physically inactive people.

Beside somatic symptoms, psychological and neurological symptoms are significantly associated with a lack of physical activity. Physical inactivity enhances depressive symptoms, anxiety disorders and decreases mood [6]. Some studies assert the case for a significant impact of physical inactivity on the development of dementia and Alzheimer disease [5].

Lifetime physical inactivity has consequently not only fatal health consequences; it accelerates the secondary ageing process and has a large impact in shortening average life expectancy [2].

\section{The Concept of Evolutionary Medicine}

As pointed out above, physical inactivity is quite common among contemporary Homo sapiens in industrialized countries. Considering the adverse health effects of an inactive lifestyle, we can conclude that a lack of physical activity or exercise — in other words, the recent sedentary lifestyle - is maladaptive. In order to analyze and perhaps explain this adverse behavior, we have to look back to the evolutionary past of Homo sapiens. The scientific discipline focusing on how differences between present circumstances and the adaptively relevant environment (ARE) may contribute to diseases is Darwinian or evolutionary medicine. However, what does Darwinian or evolutionary medicine mean?

Today evolutionary theory is without any doubt an unquestionable part of natural science. The term evolution — although much older — is mainly associated with the name of Charles Darwin (1809-1882), who introduced the terms biological evolution, and natural and sexual selection in science. More than 150 years after the publication of Charles Darwin's fundamental work "On the Origin of Species by Means of Natural Selection" in 1859 [22] and 140 years after publication of "The Descent of Man and Selection in Relation to Sex" in 1871 [23], the Darwinian approach is becoming more and more established in medical science. Soon after Darwin's death in 1882, a Darwinian theory of disease was introduced by a group of physicians. These early ideas, however, had nothing to do with the principles of recent evolutionary medicine. Benjamin Ward Richardson used the term Darwinian medicine for the first time in 1893; however, he was speaking about the medicine of Erasmus Darwin, the grandfather of Charles Darwin, and not about the application of evolutionary theory on recent patterns of health and disease [24]. More than 90 years after Darwin's death, Theodosius Dobzhansky pointed out the importance of the concept of evolution to explain all natural phenomena: "Nothing in biology makes sense except in the light of evolution" [25]. Consequently, evolutionary or ultimate explanations for each condition are necessary [26]. Proximate and ultimate explanations represent the different levels of causality in biology. Proximate causes are immediate mechanisms such as physiological or fetal and embryologic factors of disease, disorders or malfunctions. Ultimate explanations, in contrast, have attempted to find the reasons behind recent diseases in our history or evolutionary past.

In case of medical conditions, Darwinian interpretations may lead to a better understanding of current health care issues. In the 1960s and 1970s, so called non-communicable diseases such as type 2 
diabetes, coronary heart disease, breast cancer and colon cancer were identified as the main causes of morbidity and mortality in Western societies. Consequently, the term "Western diseases" was introduced [27]. In 1962, James Neel introduced the so called Thrifty Genotype theory. According to Neel's hypothesis, a Thrifty genotype evolved under conditions of feast and famine during Paleolithic times. In a Western environment, however, a Thrifty genotype would make people vulnerable to typical Western diseases such as type 2 diabetes and obesity [28]. Although the concept of a Thrifty genotype was subject to major criticism and was modified by Neel himself as well as other authors, the idea that recent diseases are the consequence of changing environments during the evolution of Homo sapiens stayed alive. The rise of Western diseases was still interpreted as a result of changing nutritional habits, characterized by a diet rich in fats and sugar, but also by reduced levels of physical activity. Modernization and especially Westernization were seen as the major reasons behind this trend. During the early 1990s, the concept of Darwinian, or better, evolutionary medicine in a recent sense was formalized by the evolutionary biologist George C. Williams and psychiatrist Randolph Nesse [29].

Williams and Nesse tried to understand why natural selection has left the human body so vulnerable to diseases [29]. According to Williams and Nesse, human biology is designed for Stone Age conditions. Modern environments may cause many diseases, such as deficiency syndromes, the effects of excess consumption of normal scare nutrients such as fats or salt, but also psychological reactions to recent life circumstances [29]. The first concept of evolutionary medicine was based on the assumption that many medical conditions that are clearly pathological today have been adaptive in the ancestral environment in which Homo sapiens evolved and thus have been selected positively for. Consequently, the aim of evolutionary medicine was to identify and understand these conditions. After the initial publication of Williams and Nesses ideas, the concept and applications of evolutionary medicine experienced their own evolution. Today, mainly the effects of changing living conditions initiated by the processes of modernization and acculturation on patterns of health and disease are focused on [30-33].

Focusing on the lifestyle of our ancestors, evolutionary medicine is able to provide insights into the origins of non-communicable diseases, such as metabolic diseases, diabetes and obesity typical for the second half of the 20 th century and the beginning of the 21 st century [34,35]. In the case of physical inactivity, we have to analyze physical activity among our ancestors and the factors which are responsible for the reduction of physical activity in recent times.

\section{The Evolution of the Genus Homo with Special Respect to Physical Activity Patterns}

There is no doubt that recent Homo sapiens have a long evolutionary history. All recent people are members of the genus Homo, which first appeared more than 2.4 million years ago in an Eastern African savanna habitat [36]. All species of the genus Homo are characterized by an obligatory bipedal locomotion, rapid encephalisation, advanced hunting technology, and the ability of making stone tools. With the appearance of Homo erectus/ergaster about 2 million years ago, marked changes in social behavior and dieting habits occurred. Increased brain size and larger body size made increased energy supply essential. This increased demands of energy to meet the metabolic costs of the energy expensive brain resulted in numerous anatomical as well as behavioral adaptations [37,38]. A high 
degree of physical activity was essential for survival for members of early Homo. The motivating factors for a physically active lifestyle were hunger, thirst and danger. Hunting, collecting food, looking for drinking water and shelter made a high degree of physical activity essential for surviving. Furthermore, anatomical and physiological changes associated with obligatory bipedalism enabled Homo erectus to walk and run long distances. From an anatomical point of view, the long legs, relative small feet with short toes, plantar arch, long spring-like tendons, such as the Achilles tendon, an enlarged gluteus maximus provided stabilization and energy for a biped locomotion [39-41]. The loss of body fur and an increasing number of eccrine sweat glands enhanced thermoregulation and protected humans from overheating [42-44]. In order to save energy for the energetic costly brain, the size of the energy-expensive gut was reduced and nutritional habits changed towards increased meat and fat consumption [37,38]. Meat consumption requires hunting or scavenging $[45,46]$. In a hot and dry habitat, about 2 million years ago humans were only able to kill animals successfully using persistence hunting. This means hunters have to keep their prey above trot-gallop transition for several hours, driving the animal into hyperthermia and then killing the exhausted animal more or less safely. This kind of hunting was only possible for trained endurance runners. Physiological and anatomical adaptations enabled members of the genus Homo to walk and especially run long distances in a dry and hot habitat. Such kind of endurance running is unique among large mammals. Most mammals are good at sprinting, either because they are predators that rely on speed and agility or because they are prey, which need to escape their predators [41]. However, galloping and even trotting mammals quickly suffer from overheating and fatigue [47,48]. The ability for walking long distances and endurance running was a clear advantage for early humans because physical activity was absolutely necessary for survival, and consequently, successful reproduction.

About 100,000 years ago, modern Homo sapiens originated in Africa and colonized, with the exception of Antarctica, the whole world. Up to now, it is not completely clear whether modern Homo sapiens had replaced earlier hominin occupants or whether modern Homo sapiens may have interbred with them [36]. Modern Homo sapiens have adapted to widely different habitats and showed a huge developmental plasticity to survive and reproduce successfully under very different environmental circumstances. The lifestyle of Homo sapiens and his ancestors was characterized by a foraging subsistence based on hunting and gathering, a lack of domesticated animals with the exception of the $\mathrm{dog}$, the use of stone and wooden tools, a mobile (nomadic) lifestyle, and small multi-aged egalitarian groups consisting of 20-30 group members.

\section{The Environment of Evolutionary Adaptedness}

Evolutionary medicine interprets several medical conditions and common diseases as the result of a mismatch between the environment in which our ancestors evolved and the recent living conditions. The evolutionary psychologist Bowlby defined the Paleolithic period when the genus Homo evolved as the "environment of evolutionary adaptedness" (EEA) [49]. According to the concept of the environment of evolutionary adaptedness, human biology has adapted through the process of natural selection to the environmental conditions during the Paleolithic period. This view is summarized by the notion that "Human biology is designed for Stone Age conditions" as Williams and Nesse pointed out. According to the concept of Bowlby, human evolution ended with the end of the Paleolithic period 
and the rise of Neolithic transition more than 10,000 years ago. The environment during the Paleolithic period was not static. During this period, climate change but also some cultural evolution occurred. On the other hand, human evolution did not stop abruptly with the rise of Neolithic transition about 10,000 years ago. Consequently, the powerful concept of an environment of evolutionary adaptedness has been criticized on a number of counts. Twenty-five years after Bowbly defined the environment of evolutionary adaptedness, William Irons introduced the new concept of the "adaptively relevant environment" considering the weaknesses of the old concept [50]. Additionally, the concept of a mismatch between our genetic heritage and our recent lifestyle was raised by Gluckman and Hanson [51]. Nevertheless, our life circumstances have changed dramatically, not only since Paleolithic times but also during the last 10,000 years and even during the last decades. However, what does this mean for physical activity?

\section{Physical Activity Levels in the Adaptively Relevant Environment}

There is no doubt that physical activity levels were quite high among late Paleolithic populations [52]. Activities included walking and running in order the gather foods, hunting, following wounded prey, or migrating to a new base camp or water whole. Additionally, carrying game, meat, or children and gathering goods, as well as tool making, meat butchering, and digging roots were typical subsistence activities. Cultural activities such as dancing and playing were common [7]. For our ancestors, the motivating factors for a physically active life style were not a desire for activity; the motivations were hunger and thirst. Physical activity was a major part of their lives because it was essential for surviving. Only physically active individuals were able to survive long enough to reproduce successfully and bring up their offspring to reproductive age. Consequently physical activity was an adaptive behavior. Of course, it is not possible to reconstruct physical activity patterns from skeletal remains in detail; however, we can state that our Upper Paleolithic ancestors showed a higher skeletal robustness indicating a highly active life style. Another possibility to reconstruct physical activity patterns of our ancestors are ethnographic analyses of recent foragers but also traditional horticulturalists, pastoralists and farmers. Ethnographic analyses of the few remaining contemporary forager populations such as the Hadza in Tanzania, the !Kung of Namibia and Botswana, Ache of Paraguay or Efe of central Africa provided information about lifestyle, in particular diet and physical activity patterns in a foraging economy $[53,54]$. Most Australian Aborigines today live a Westernized lifestyle characterized by the consumption of Western foods and physical inactivity; however, O'Dea [55] was able to provide some glimpses into the traditional way of life of Australian Aborigines populations. She described the lifestyle of these hunter-gatherer populations as a physically active one. Physical activity was characterized by walking long distances, digging in rocky grounds for tuber, reptiles, eggs and water deep below the surface, chopping with a stone axe, gathering and carrying firewood. Among Australian Aborigines following a traditional hunter gatherer lifestyle, non-communicable diseases ware nearly unknown. Among their Westernized counterparts, obesity and type 2 diabetes are prevalent and much more common than among Australians of European origin [55]. Physical activity among recent hunter gatherers is also associated with increased reproductive success. The analysis of reproductive success among contemporary forager populations such as Ache, Hadza, !Kung, Lamalera, and Meriam revealed that successful hunters, i.e., physically highly active 
males had significantly more surviving offspring [56,57]. Nevertheless, we have to be aware that a typical hunter-gatherer lifestyle is mainly extinct today. With the exception of few secluded tribes in Amazon rainforests and on the Andaman Islands, non-modernized hunter-gatherer populations no longer exist [58]. Information concerning the typical hunter-gatherer lifestyle came from ethnographic studies carried out during the 1960s and 1970s. The typical lifestyle was described as a highly mobile one because high levels in daily activity in search of food, water and sleeping sites are necessary. In addition, hunter-gatherer women often had to carry their young children for long distances. The average hunter-gatherer mother carried her child until she or he was about 4 years old, covering upwards of 3500 kilometers with the child on her back or in her arms during this time [59]. Concerning nutritional habits, it is well documented that diets consist to a high degree of vegetable food, protein $(50 \%-80 \%)$ and a low fat content [60,61]. From a medical point of view, typical non-communicable diseases such as hypertension, heart disease, cancer, diabetes or obesity are rather unknown [62-67]. Homo sapiens are clearly adapted to an environment like this.

This kind of lifestyle however changed dramatically. About 20,000 years ago, the process of Neolithic transition began to result in the emergence of agriculture, followed by a complete change in subsistence economy and life circumstances about 10,000 years ago in the area of the Fertile Crescent [68]. Neolithic transition changed human lifestyle dramatically [69]. Domestication of animals and plants allowed the production of a surplus of food. Consequently, humans developed semi-permanent settlements and gave up their mobile lifestyle. The production of food allowed a considerable population growth because more people could be supported on the food grown. On the other hand, the adoption of agriculture and animal husbandry led to dramatic dietary changes. Dietary breadth was reduced dramatically and diet consisted of high carbohydrate crops such as rice, barley or wheat and tuber such as potatoes [70]. Analyses of Neolithic skeletal remains indicate protein deficiencies and periodic food shortages, skeletal conditions which can clearly be interpreted as results of famine and starvation. Furthermore, domestication of animals and plants changed the environments dramatically. The use of feces as fertilizer and the construction of irrigation increased the contact with parasites. Additionally, the close proximity to domesticated animals exposed humans to a variety of new pathogens resulting in an increased frequency of infectious diseases [69,70]. Beside the increased incidence of infectious diseases, changes in lifestyle patterns during the Neolithic transition resulted in the appearance of non-communicable diseases. The Horus study using CT scans of artificial natural mummies of four ancient populations yielded high prevalence rates of atherosclerosis among post Neolithic ancient Egyptians, ancient Peruvians and ancestral Puebloans of the South-West US. Additionally, atherosclerosis was found among natural mummies of Unangan hunter-gatherers from the Aleut Islands [71]. At a first glimpse, atherosclerosis among ancient hunter gatherers seems surprising; however, we should not forget that hunter-gatherers from arctic regions are characterized by a high fat diet. The prevalence of atherosclerosis among post-Neolithic populations however indicates the major lifestyle changes associated with Neolithic transition. Therefore, Neolithic transition has led to the so called first epidemiologic transition [72,73]. Beside changes in nutritional habits, physical activity patterns changed. It can be assumed that this was especially true of males. During the late Paleolithic, male physical activity patterns can be described as walking, endurance running, hunting, and meat butchering, while late Paleolithic females showed a wide range of physical activities, mainly digging, picking, cutting and carrying [7]. Contemporary gender differences in 
sporting activities may be due to these gender typical activity patterns during the late Paleolithic era $[74,75]$. With the Neolithic transition, male activities changed from hunting to activities in agriculture such as field preparation, planting, digging, weeding, harvesting, conversion of crops to food, feeding animals, milking, and building huts and stables. These kinds of physical activities are more or less equal to female activities [7]. Consequently, sexual size dimorphism and sexual dimorphism in skeletal robustness decreased $[68,76]$. Although physical activity patterns changed with Neolithic transition, there was still an obligatory and natural linkage between caloric acquisition as food energy, and caloric expenditure as physical activity [16]. These kinds of physical activity patterns established during the Neolithic transition remained more or less stable until the Industrial Revolution starting at the end of 18 th century.

\section{Issues of Recent Environment}

The obligatory and natural linkage between food acquisition and physical activity ended during the 19 th century due to the Industrialized Revolution. During the 20th and 21 st century, the circumstances of human existence changed dramatically, especially during the last few decades. There is no doubt that living standard and health standard has improved during the 20th and 21st century. Neonatal and childhood mortality dropped down, life expectancy increased dramatically. Infectious diseases declined and improved hygiene, nutrition and medical care led to the so called third epidemiologic transition. While infectious diseases declined, so called non-communicable diseases and diseases typical of old age increased dramatically. The new burdens are diabetes type 2, cardiovascular disease, cancer, osteoporosis, sarcopenia, frailty, psychological problems and dementia [35]. As pointed out above, these diseases are highly related to a physically inactive lifestyle [2,3]. We have to be aware that our recent environment is completely different from that in which our species evolved. An increasing number of people live in urban environments, many of them in so-called mega cities of more than 10 million inhabitants. Recent urban Homo sapiens live alone or in small nuclear families in a quite anonymous society. Technical advances and modernization of lifestyle have resulted in a marked transition in human lifestyle [1]. Exemplary, medical interventions and practices have significantly changed human morbidity and mortality. The daily energy effort to gather and prepare enough food is reduced nearly to zero, since only few individuals are working in food production. Mechanized transportation, sedentary jobs and labor-saving household technologies reduce physical activity too. A sedentary, completely physically inactive lifestyle prevails in all industrialized postmodern societies. This is also true of children and adolescents although modern children still have a significant desire for physical activity. Western societies however hinder them to act out their desire for physical activities. Children are taken to kindergarten and school by car, and have to sit still in kindergarten and classrooms. They have to stay in the house instead of playing outside. While $26 \%$ of 8-16 year old US children watch TV for at least 4 hours per day and 67\% watch TV for at least 2 hours per day, only $19 \%$ of high school students are physically active for 20 minutes or more in daily physical education classes. Sixty percent of US adults are not regularly active and $25 \%$ are not active at all [77]. However, how different are these recent activity patterns from that of our ancestors or that of recent traditional societies? 
Table 1. Estimated physical activity levels (PAL) in non-human primates, human ancestors, contemporary foragers and members of affluent societies (adapted from Malina and Little 2008, [7] Cordain et al. 1997 [63], Dugas et al. 2011[78]).

\begin{tabular}{|c|c|c|c|c|c|}
\hline \multirow[t]{2}{*}{ Sample } & \multicolumn{2}{|c|}{ Male } & \multicolumn{2}{|c|}{ Female } & \multirow[t]{2}{*}{ Source } \\
\hline & PAL & TEE & PAL & TEE & \\
\hline \multicolumn{6}{|l|}{ Non-human primates } \\
\hline Pan troglodytes & 1.46 & 1510 & 1.36 & 1144 & Cordain et al. [63] \\
\hline \multicolumn{6}{|l|}{ Hominids } \\
\hline Australopithecus afarensis & 1.59 & 1741 & 1.59 & 1248 & Leonard \& Robertson [79] \\
\hline Homo habilis & 1.70 & 1954 & 1.70 & 1322 & Leonard \& Robertson [79] \\
\hline Homo erectus & 2.02 & 2289 & 1.53 & 1975 & Leonard \& Robertson [79] \\
\hline Homo sapiens & 2.02 & 2346 & 1.54 & 2026 & Leonard \& Robertson [79] \\
\hline \multicolumn{6}{|l|}{ Recent hunter-gatherers } \\
\hline !Kung & 1.68 & 2319 & 1.56 & 1712 & Leonard [80] \\
\hline Ache & 2.17 & 3327 & 1.88 & 2626 & Leonard $[80]$ \\
\hline Hadza & 2.26 & 2649 & 1.78 & 1877 & Pontzer et al. [81] \\
\hline Igloolik inuit & 2.20 & - & 1.80 & - & Dugas et al. [78] \\
\hline \multicolumn{6}{|l|}{ Forager horticulturalist } \\
\hline Huli & 1.84 & 3138 & 1.88 & 2639 & Yamauchi et al. [82] \\
\hline Machiguena & 2.14 & 3200 & 1.67 & 1925 & Gurven et al. [83] \\
\hline Tsimane & 2.15 & - & 1.85 & - & Gurven et al. [83] \\
\hline Shuar & 1.54 & 2176 & 1.42 & 2033 & Madimenos et al. [84] \\
\hline Yakut & 1.68 & 3101 & 1.50 & 2298 & Snodgrass et al. [85] \\
\hline \multicolumn{6}{|l|}{ Pastoralists } \\
\hline Evenki, Sibiria & 1.80 & 2815 & 1.61 & 2056 & Leonard et al. [86] \\
\hline Massai & 1.95 & - & 1.99 & - & Christensen et al. [87] \\
\hline \multicolumn{6}{|l|}{ Agriculture (traditional farmers) } \\
\hline Luo & 1.93 & - & 1.81 & - & Christensen et al. [87] \\
\hline Aymara & 2.18 & 2806 & 2.26 & 2808 & Kashiwazaki et al. [88] \\
\hline Kamba & 1.95 & - & 1.90 & - & Christensen et al. [87] \\
\hline \multicolumn{6}{|l|}{ Modern societies } \\
\hline Low Human development index & 1.88 & 2937 & 1.70 & 2221 & Dugas et al. [78] \\
\hline High Human development index & 1.79 & 3033 & 1.71 & 2388 & Dugas et al. [78] \\
\hline
\end{tabular}

Legend: PAL $=$ ratio of total energy expenditure (TEE) to basal metabolic rate (BMR) or resting energy expenditure $(\mathrm{REE}) ; \mathrm{TEE}=$ total energy expenditure $(\mathrm{kcal} / \mathrm{d})$.

In order to compare physical activity patterns, standardized physical activity levels can be used. Physical activity levels (PAL) can be calculated by the ratio of total energy expenditure (TEE) to basal metabolic rate (BMR) or resting energy expenditure (REE) [7]. PAL is a commonly used indicator of changing activity patterns. Table 1 presents physical activity levels (PAL) and total energy expenditure ( $\mathrm{kcal} / \mathrm{d})$ of non-human primates through our hominid ancestors to contemporary Homo sapiens. Before we start to discuss the impact of subsistence patterns on PAL and TEE, we have to consider the weakness of both parameters. Physical activity is defined as any bodily movement produced by skeletal muscles that results in energy expenditure [89]. Physical activity induced energy expenditure 
however is determined by body movement, body weight and body size [89,90]. In general, it requires more energy to move a large and heavy body than a small and lean one. This is one of the reasons why obese persons move less than lean ones. In the present study, PAL and TEE of different populations are compared. It must be taken into account that traditional populations, in particular hunter and gatherers, living under poor socioeconomic conditions in marginalized environments today are generally shorter and leaner than recent people following a Westernized way of life. These somatic differences should not be forgotten when interpreting differences in PAL and TEE between different recent populations. As to be seen in Table 1, PAL was nearly always higher among males than among females. This was also true of total energy expenditure (TEE). Males nearly always surpassed their female counterparts. These gender differences may be due to gender typical differences in daily workload but also differences in body size. In every recent population, males are taller and heavier on average than females. These differences in body size and body composition may contribute to gender differences in PAL and TEE. Among recent traditional populations, physical activity levels ranged from 1.54-2.26 among males and between 1.42 and 2.26 among females. Concerning total energy expenditure, highest values were found for recent hunter and gatherer populations such as the Ache and forager horticulturalists such as the Huli and Machiguenga. Among these populations, the average PAL was also high. Among contemporary people in modern societies with a low Human Development Index (HDI), the average physical activity levels were 1.88 for males and 1.70 for females. Among modern societies with a high Human Development Index (HDI), average PAL was 1.79 for males and 1.71 for females [78]. At a first glimpse, differences in PAL as well as total energy expenditure (TEE) between populations following different subsistence patterns are quite low. It seems surprising that lowest PALs and TEEs were found among two hunter gatherer groups, in particular among !Kung San in Southern Africa and Shuar, indigenous forager-horticulturalists in Ecuador. These observations consequently may implicate that physical activity levels have not much changed with modernization. This view is corroborated by the PALs and TEEs estimated for fossil hominids. Concerning fossil hominids, we should not forget, however, that PALs and TEEs are not based on real physiological parameters and are only estimated. Furthermore, fossil hominids and also recent forager populations are significantly shorter and leaner than Western populations. This may explain the low differences in PAL and TEE between people following a traditional lifestyle and Western populations. Furthermore, concerning recent so called hunter-gatherer populations, we should bear in mind that most of them live in marginalized environments and have adopted Westernized lifestyles to some extent, which might have affected physical activity levels. This is true of the Shuar in Ecuador [84]. Modernization and Westernization has resulted in a decrease in physical activity levels and also in an increase in obesity rates and the prevalence of non-communicable diseases. The Bolivian Tsimane still living as forager-horticulturalists in the Amazon region display relatively high average PALs (1.85 among females, 2.15 among males) which are typical of other subsistence populations (see Table 1). Unfortunately, there are no TEE values of Tsimane people available. Nevertheless, increasing socioeconomic change has increased obesity rates although physical activity seems not to be affected by this trend [83]. We have to be aware that the process of modernization affects first nutritional habits, and later on physical activity patterns. As pointed out above, typical hunter-gatherer lifestyles became more or less extinct during the 20th century. Traditional farmers and pastoralists have also undergone a process of Westernization. Nevertheless, the PALs of pastoralists and traditional farmers 
were generally higher than PALs of affluent societies. Therefore, the conclusion that can be made from studying recent traditional societies is that physical activity plays only a minor role in the development of non-communicable diseases is not correct. We can assume that Homo sapiens is adapted to a physically active lifestyle; our indoor, overfed sedentary existence, however, is maladaptive and may result in an increased risk of many diseases as mentioned above. However, why have Homo sapiens changed physical activity patterns? For the most part of our evolution and history, physical activity was essential for surviving. Except for children under age 5 and those who were disabled, sick or too old, everyone did a wide variety of physical activities every day in order to fight against hunger and thirst [58]. As to be seen in Table 1, even after the adoption of agriculture, physical activity levels remained high. Additionally, energy was needed to maintain homeostasis, in particular a stabile body temperature. Among human females, reproduction required considerable energy. Without any doubt, this lifestyle was exhausting and therefore every possibility to conserve energy by reduction of physical activity was taken. This was true of not only Paleolithic times, but also of the Neolithic period up to now. This behavior seems to be coded in the genome of Homo sapiens. In our recent environment, however, this behavior is clearly maladaptive. From a Darwinian viewpoint, the tendency to reduce physical activity can be understood as a result of the mismatch between our behavioral heritage and our recent environment.

\section{Conclusions}

We are faced with a dramatic mismatch between the current environment and the environment in which the human body has evolved. Ninety-nine percent of our evolutionary history we have spent as hunter-gatherers following a highly mobile lifestyle in small groups. Our gene pool was shaped by natural and sexual selection towards an optimal adaptation to these environments and life circumstances, which nowadays no longer exist. Consequently, modern life in affluent industrialized societies fosters the development of chronic, non-communicable diseases and thus makes life sometimes rather uncomfortable. Evolutionary medicine interprets numerous recent diseases from back pain, allergies, problems during childbirth to metabolic syndrome, psychological disorders as well as senescence associated diseases as a consequence of this mismatch between recent environments and our genetic heritage [34,91]. What can we do? We are clearly adapted to a physical, highly active lifestyle. Living in urban environments, physical activity has diminished, and there is no possibility to turn the wheel back. The physical effort required in work and occupation has decreased steadily. Cars, public transportation, elevators, internet shopping, and the trend of cocooning promote a sedentary lifestyle. Therefore, our only chance to increase physical activity is sporting activity during leisure time. This is a quite young activity pattern in the history of Homo sapiens. Our ancestors had no desire for physical activities; it was just a question of survival to move. We are born to move, to walk, to run, and now we have to incorporate these kinds of activities into our leisure time. For the first time in our evolution and history, we have to be physically active, not in order to find shelter or food, but for staying healthy. This is a completely new challenge for Homo sapiens.

\section{Conflicts of Interest}

The author declares no conflict of interest. 


\section{References}

1. Mattson, M.P. Evolutionary aspects of human exercise-Born to run purposefully. Ageing Res. Rev. 2012, 11, 347-352.

2. Booth, F.W.; Laye, M.J.; Roberts, M.D. Life time sedentary life accelerates some aspects of secondary ageing. J. Appl. Physiol. 2011, 111, 1497-1504.

3. Booth, F.W.; Lees, S.J. Fundamental questions about genes, inactivity and chronic diseases. Physiol. Genomics 2007, 28, 146-157.

4. Booth, F.W.; Chakravarthy, M.V.; Spangenburg, E.E. Exercise and gene expression: Physiological regulation of the human genome through physical activity. J. Physiol. 2002, 543, 399-411.

5. Lautenschlager, N.T.; Almeida, O.P. Physical activity and cognition in old age. Curr. Opin. Psychiatry 2006, 19, 190-193.

6. Warburton, D.E.; Nicol, C.W.; Bredin, S.S. Health benefits of physical activity: The evidence. CMAJ 2006, 174, 801-809.

7. Malina, R.M.; Little, B.B. Physical activity: The present in the context of the past. Am. J. Hum. Biol. 2008, 20, 373-391.

8. Haslam, D. Obesity: A medical history. Obes. Rev. 2007, 8, 31-36.

9. Hahn, R.A.; Teutsch, S.M.; Rothenberg, R.B.; Marks, J.S. Excess deaths from nine chronic diseases in the United States. JAMA 1986, 264, 2654-2659.

10. Mokdad, A.H.; Marks, J.S.; Stroup, D.F.; Gerberding, J.L. Actual causes of death in the United States, 2000. JAMA 2004, 291, 1238-1245.

11. Lee, I.M.; Shiroma, E.J.; Lobelo, F.; Puska, P.; Blair, S.N.; Katzmarzyk, P.T. Effect of physical inactivity on major non-communicable diseases worldwide: An analysis of burden of disease and life expectancy. Lancet 2012, 380, 219-229.

12. Cordain, L.; Gotshall, R.W.; Eaton, S.B.; Eaton, S.B. Physical activity, energy expenditure and fitness: An evolutionary perspective. Int. J. Sports Med. 1998, 19, 328-335.

13. Caballero, B. The global epidemic of obesity: An overview. Epidemiol. Rev. 2007, 29, 1-5.

14. Frisch, R.E.; Wyshal, G.; Albright, N.L.; Albright, T.E.; Schiff, I.; Jones, K.P. Lower prevalence of breast cancer and cancers of the reproductive system among former college athletes compared to non-athletes. Br. J. Cancer 1985, 52, 885-891.

15. Dirx, M.J.M.; Voorrips, L.E.; Goldbohm, R.A.; van den Brandt, P.A. Baseline recreational physical activity, history, of sports participation and postmenopausal breast carcinoma risk in the Netherlands cohort study. Cancer 2001, 92, 1638-1649.

16. Eaton, S.B.; Eaton, S.B. An evolutionary perspective on human physical activity: Implications for health. Comp. Biochem. Physiol. A 2003, 136, 153-159.

17. Rizzoli, R.; Bianchi, M.L.; Garabedian, M.; McKay, H.A.; Moreno, L.A. Maximizing bone mineral mass gain during growth for the prevention of fractures in the adolescents and the elderly. Bone 2010, 46, 294-305.

18. Rosenberg, I.H. Summary comments. Am. J. Clin. Nutr. 1989, 50, 1231-1233.

19. Mühlberg, W.; Sieber, L. Sarcopenia and frailty in geriatric patients, Implications for training and prevention. Z. Gerontol. Geriatr. 2004, 37, 2-8. 
20. Clarke, M.S.F. The effects of exercise on skeletal muscle in the aged. J. Musculoskelet. Neuronal Interact. 2004, 4, 175-178.

21. Reid, K.F.; Naumova, E.N.; Carabello, R.J.; Philips, E.M.; Fielding, R.A. Lower extremity muscle mass predicts functional performance in mobility-limited elders. J. Nutr. Healthy Ageing 2008, 12, 493-498.

22. Darwin, C. On the Origin of Species by Means of Natural Selection; John Murray: London, UK, 1859.

23. Darwin, C. The Descent of Man and Selection in Relation to Sex; John Murray: London, UK, 1871.

24. Zampieri, F. Origins and History of Darwinian Medicine. Humana Mente 2009, 9, 13-38.

25. Dobzhansky, T. Nothing in Biology makes sense except in the light of evolution. Am. Biol. Teach. 1973, 35, 125-129.

26. Voland, E. Grundriss der Soziobiologie; Fischer Verlag: Stuttgart, Germany, 1993.

27. Pollard, T.M. Western Diseases. An Evolutionary Perspective; Cambridge University Press: Cambridge, UK, 2008.

28. Neel, J.V. Diabetes mellitus: A thrifty genotype rendered detrimental by progress? Am. J. Hum. Genet. 1962, 14, 353-362.

29. Williams, G.C.; Nesse, R.M. The dawn of Darwinian medicine. Q. Rev. Biol. 1991, 66, 1-22.

30. Fuller, J. Darwinian Medicine: The past and present state of medicine's unifying Science. UTMJ 2011, 88, 209-214.

31. Harris, E.E.; Malyango, A.A. Evolutionary explanations in medical and health profession courses: Are you answering your students "why" questions? BMC Med. Educ. 2005, 5, 16-23.

32. Nesse R.M.; Williams, G.C. Why We Get Sick: The New Science of Darwinian Medicine; Vintage Books: New York, NY, USA, 1994.

33. Nesse, R.M.; Stearns, S.C. The great opportunity: Evolutionary applications to medicine and public health. Evol. Appl. 2008, 1, 28-48.

34. Trevathan, W.R.; McKenna, J.J.; Smith, E.O. Evolutionary Medicine; Oxford University Press, New York, USA: 1999.

35. Trevathan, W.R. Evolutionary medicine. Ann. Rev. Anthropol. 2007, 36, 139-154.

36. Henke, W.; Hardt, T. The genus Homo: Origin, speciation and dispersal. In Continuity and Discontinuity in the Peopling of Europe: One Hundred Fifty Years of Neanderthal Study, Vertebrate Paleobiology and Paleoanthropology; Condemi, S., Weniger, G.-C., Eds.; Springer: New York, NY, USA, 2011; pp. 17-43.

37. Aiello, L.C.; Wells, J.C.K. Energetics and the evolution of the genus Homo. Ann. Rev. Anthropol. 2002, 31, 323-338.

38. Aiello, L.C.; Wheeler, P. The expensive tissue hypothesis: The brain and the digestive system in human and primate evolution. Curr. Anthropol. 1995, 36, 199-221.

39. Lieberman, D.E.; Raiclen, D.A.; Pontzer, H.; Bramble, D.M.; Cutright-Smith, E. The human gluteus maximus and its role in running. J. Exp. Biol. 2006, 209, 2143-2155.

40. Rolian, C.; Lieberman, D.E.; Hamill, J.; Scott, J.W.; Werbel, W. Walking, running and the evolution of short toes in humans. J. Exp. Biol. 2009, 212, 713-721.

41. Lieberman, D.E.; Bramble, D.M. The evolution of marathon running: Capabilities in humans. Sports Med. 2007, 37, 288-290. 
42. Newman, R.W. Why is man such a sweaty, thirsty, naked animal? Hum. Biol. 1970, 42, 12-27.

43. Ruxton, G.D.; Wilkinson, D.M. Thermogregulation and endurance running in extinct hominins: Wheeler's models revisted. J. Hum. Evol. 2011, 61, 169-175.

44. Wheeler, P.E. The thermoregulatory advantages of hominid bipedalism in open equatorial environments: The contribution of increased convective heat loss and cutaneous evaporative cooling. J. Hum. Evol. 1991, 21, 107-115.

45. Liebenberg, L. Persistence hunting by modern hunter-gatherers. Curr. Anthropol. 2006, 47, 1017-1025.

46. Pickering, T.R.; Bunn, H.T. The endurance running hypothesis and hunting and scavenging in savanna-woodlands. J. Hum. Evol. 2007, 53, 434-438.

47. Steudel-Numbers, K.L.; Wall-Scheffler, C.M. Optimal running speed and the evolution of hominin hunting strategies. J. Hum. Evol. 2009, 56, 355-360.

48. Farley, C.T.; Glasheen, J.; McMahon, T.A. Running springs: Speed and animal size. J. Exp. Biol. 1993, 185, 71-86.

49. Bowlby, J. Attachment and Loss; Basic Books: New York, NY, USA, 1969.

50. Irons, W. Adaptively relevant environments versus the environment of evolutionary adaptedness. Evol. Anthropol. 1998, 6, 194-204.

51. Gluckman, P.; Hanson, M. Mismatch: Why Our World No Longer Fits Our Bodies; Oxford University Press, New York USA: 2006.

52. Bramble, D.M.; Lieberman, D.E. Endurance running and the evolution of Homo. Nature 2004, $432,345-352$.

53. Marlowe, F.W. The Hadza Hunter Gatherers of Tanzania; University of California Press: Los Angeles, CA, USA, 2010.

54. Howell, N. Life Histories of the Dobe !Kung. Food, Fatness and Well-Being over the Life-Span; University of California Press: Los Angeles, CA, USA, 2010.

55. O’Dea, K.; Hopper, J.; Patel, M.; Traimedes, K.; Kubisch, D. Obesity, diabetes and hyperlipidemia in a Central Australian Aboriginal community with a long history of acculturation. Diabetes Care 1993, 16, 1004-1010.

56. Kaplan, H.; Hill, K. Hunting ability and reproductive success among male Ache foragers: Preliminary results. Curr. Anthropol. 1985, 26, 131-133.

57. Smith, E.A. Why do good hunters have higher reproductive success? Hum. Nat. 2004, 15, 343-364.

58. O'Keefe, J.H.; Vogel, R.; Lavie, C.J.; Cordain, L. Exercise like a hunter-gatherer. A prescription for organic physical fitness. Prog. Cardiovasc. Dis. 2011, 53, 471-479.

59. Panter-Brick, C. Sexual division of labor: Energetic and evolutionary scenarios. Am. J. Hum. Biol. 2002, 14, 627-640.

60. Konner, M.; Eaton, S.B. Paleolithic nutrition. Nutr. Clin. Pract. 2010, 25, 594-602.

61. Eaton, S.B.; Konner, M. Paleolithic nutrition: A consideration of its nature and current implications. N. Engl. J. Med. 1985, 312, 283-289.

62. Eaton, S.B.; Konner, M.; Shostak, M. Stone agers in the fast lane; chronic degenerative diseases in evolutionary perspective. Am. J. Med. 1988, 84, 739-749.

63. Cordain, L.; Gotshall, R.W.; Eaton, S.B. Evolutionary aspects of exercise. World Rev. Nutr. Diet 1997, 81, 49-60. 
64. Hockett, B.; Haws, J. Nutritional ecology and diachronic trends in Paleolithic diet and health. Evol. Anthropol. 2003, 12, 211-216.

65. Lieberman, L.S. Evolutionary and anthropological perspectives on optimal foraging in obesogenic environments. Appetite 2006, 47, 3-9.

66. Lieberman, L.S. Dietary, evolutionary and modernizing influences on the prevalence of type 2 diabetes. Ann. Rev. Nutr. 2003, 23, 345-377.

67. O'Keefe, J.H., Jr.; Cordain, L. Cardiovascular disease resulting from Diet and Lifestyle at odds with our Paleolithic genome: How to become a 21st century hunter-gatherer. Mayo Clin. Proc. 2004, 79, 101-108.

68. Maher, L.A.; Richter, T.; Macdonald, D.; Jones, M.D.; Martin, L.; Stock, J.T. Twenty thousand year old huts at a hunter gatherer settlement in eastern Jordan. PLoS One 2012, 7, e31447.

69. Larsen, C. Biological changes in human populations with agriculture. Ann. Rev. Anthropol. 1995, $24,185-213$.

70. Armelagos, G.J.; Goodman, A.H.; Jacobs, K.H. The origins of agriculture: Population growth during a period of declining health. Pop. Environ. 1991, 13, 9-22.

71. Thompson, R.C.; Allam, A.H.; Lombardi, G.P.; Wann, S.; Sutherland, M.L.; Sutherland, J.D.; Al-Tohamy Soliman, M.; Frohlich, B.; Mininberg, D.T.; Monge, J.M.; et al. Atherosclerosis across 4000 years of human history: The Horus study of four ancient populations. Lancet 2013, $381,1211-1221$.

72. Barrett, R.; Kuzawa, C.W.; McDade, T.; Armelagos, G.J. Emerging and re-emerging infectious diseases: The third epidemiologic transition. Ann. Rev. Anthropol. 1998, 27, 247-271.

73. Omran, A. The epidemiologic transition. A theory of the epidemiology of population change. Milbank Q. 1971, 49, 509-538.

74. Chalabaev, A.; Sarrazin, P.; Fontayne, P.; Boiche, J.; Clement-Guillotin, C. The influence of sex stereotypes and gender roles on participation and performance in sport and exercise: Review and future directions. Psychol. Sport Exerc. 2013, 14, 136-144.

75. Deaner, R.O. More males run fast-A stable sex difference in competitiveness in U.S. distance runners. Evol. Hum. Behav. 2006, 27, 63-84.

76. Walker, A.R.P.; Walker, B.F.; Adam, F. Nutrition, diet, physical activity, smoking and longevity: From primitive hunter gatherer to present passive consumer-How far can we go? Nutrition 2003, 19, 169-173.

77. Leonard, W.R.; Robertson, M.L. Nutritional requirements and human evolution. A bioenergetics model. Am. J. Hum. Biol. 1992, 6, 77-88.

78. Dugas, I.R.; Handers, R.; Merrili, S.; Ebersole, K.; Shobam, D.A. Energy expenditure in adults living in developing compared with industrial countries: A meta-analysis of doubly labeled water studies. Am. J. Clin. Nutr. 2011, 93, 427-441.

79. Leonard, W.R.; Robertson, M.L. Comparative primate energetic and hominid evolution. Am. J. Phys. Anthropol. 1997, 102, 265-281.

80. Leonard, W.R. Human energetic. In Encyclopedia of Energy; Cleveland, C.J., Ed.; Elsevier: New York, NY, USA, 2004; pp. 173-182.

81. Pontzer, H.; Raichlen, D.A.; Wood, B.M.; Mabulla, A.Z.P.; Racette, S.B.; Marlowe F.W. Hunter-Gatherer Energetics and Human obesity. PLoS One 2012, 7, E40503. 
82. Yamauchi, T.; Umezaki, M.; Ohtsuka, R. Physical activity and subsistence pattern of the Huli, a Papua New Guinea Highland population. Am. J. Phys. Anthropol. 2001, 11, 258-268.

83. Gurven, M.; Jaeggi, A.V.; Kaplan, H.; Cummings, D. Physical activity and modernization among Bolivian Amerindians. PLoS One 2013, 8, e55679.

84. Madimenos, F.C.; Snodgrass, J.J.; Blackwell, A.D.; Liebert, M.A.; Sugiyama, L.S. Physical activity in an indigenous Ecuadorian forager-horticulturalist population as measured using accelerometry. Am. J. Hum. Biol. 2011, 23, 4488-4497.

85. Snodgrass, J.J.; Leonard, W.R.; Tarskaia, L.A.; Schoeller, D.A. Total energy expenditure in the Yakut (Sakha) of Sibiria as measured by doubly labeled water method. Am. J. Clin. Nutr. 2006, 84, 798-806.

86. Leonard, W.R.; Katzmaryzk, P.T.; Crawford, M.H. Energetics and population ecology of Siberian herders. Am. J. Hum. Biol. 1996, 8, 275-289.

87. Christensen, D.L.; Faurholt-Jepsen, D.; Boit, M.K.; Mwaniki, D.L.; Kilonzo, B.; Tetens, I.; Kiplamai, F.K.; Cheruiyot, S.C.; Friis, H.; Borch-Johnsen, K.; et al. Cardiorespiratory fitness and physical activity in Luo, Kamba, and Maasai of rural Kenia. Am. J. Hum. Biol. 2012, 24, 723-729.

88. Kashiwazaki, H.; Uenishi, K.; Kobayabashi, T.; Rivera, J.O.; Coward, W.A.; Wright, A. Year round high physical activity levels in agropastoralists of Bolivian Andes: Results from repeated measurements of DLW method in peak and slack seasons of agricultural activities. Am. J. Hum. Biol. 2009, 21, 337-345.

89. Westerterp, K.R. Physical activity and physical activity induced energy expenditure in humans: Measurement, determinants and effects. Front. Physiol. 2013, 4, 1-11.

90. Goran, M.I. Estimating energy requirements: Regression based prediction equiations or multiples of resting metabolic rate. Public Health Nutr. 2005, 8, 1184-1186.

91. Stearns, S. Evolution in Health and Disease; Oxford University Press, New York, USA 1999.

(C) 2014 by the authors; licensee MDPI, Basel, Switzerland. This article is an open access article distributed under the terms and conditions of the Creative Commons Attribution license (http://creativecommons.org/licenses/by/3.0/). 